\title{
Clinical Pharmacology of Fentanyl in Infants and Children
}

\author{
Gian Maria Pacifici
}

Associate Professor of Pharmacology via Sant’ Andrea 32, 56127 Pisa, Italy

Corresponding Author: Gian Maria Pacifici, Associate Professor of Pharmacology via Sant' Andrea 32, 56127 Pisa.

Received date: October 11, 2021; Accepted date: November 05, 2021; Published date: January 04, 2022

Citation: Gian Maria Pacifici, (2022) Clinical pharmacology of fentanyl in infants and children. J, Clinical Case Reports and Studies 3(2); DOI: 10.31579/2690-8808/099

Copyright: (C) 2022 Gian Maria Pacifici, This is an open access article distributed under the Creative Commons Attribution License, which permits unrestricted use, distribution, and reproduction in any medium, provided the original work is properly cited.

\begin{abstract}
Fentanyl is a systemic opioid related to the phenylpiperidines, it is used in anaesthetic practice and in analgesia and the analgesic effect is about 100 times higher than that of morphine. Fentanyl is highly lipid soluble, rapidly crosses the blood-brain-barrier, and fentanyl concentrations rapidly decline in plasma and cerebrospinal fluid. Fentanyl causes respiratory depression and decreases the heart rate through vagal activation. Fentanyl may be administered intravenously, orally, by transdermal, intranasal or by buccal application and the oral bioavailability is poor. In infants, fentanyl is given for short term use, sustained use, and during therapeutic hypothermia. In children, fentanyl is given intravenously, by transdermal application, or by buccal administration and the fentanyl dose varies with the child age and body-weight. Fentanyl has been found efficacy and safe in infants and children but it may induce adverse-effects and fentanyl causes different effects in infants and children. Following intravenous administration of fentanyl to infants and children, the fentanyl elimination half-life ranges from 208 to 1,266 min and the distribution volume ranges from 1.92 to $15.2 \mathrm{~L} / \mathrm{kg}$. Such variability is due to the wide variation of subject's demographic characteristics. Fentanyl interacts with drugs, the treatment and trials with fentanyl have been studied in infants and children. Fentanyl freely crosses the human placenta and poorly migrates into the breast-milk. The aim of this study is to review fentanyl dosing, efficacy, safety, effects, adverse-effects, metabolism, pharmacokinetics, drug interaction, treatment, and trials in infants and children, and fentanyl placental transfer and migration into the breast-milk.
\end{abstract}

Key Words: fentanyl; dosing; efficacy and safety; effects; adverse-effects; metabolism; pharmacokinetics; drug interaction; treatment, trials; placenta; breast-milk; infants; children

\section{Introduction}

Mechanism of fentanyl action

Fentanyl is a systemic opioid related to the phenylpiperidines. The actions of fentanyl and its congeners sulfentanil, remifentanil, and sulfentanil are similar to those of other MOR agonists. Fentanyl and sulfentanil are important drugs in anaesthetic practice because of their relatively short time to peak analgesic effect, rapid termination of effect after small bolus doses, cardiovascular safety, and capacity to significantly reduce the dosing requirement for the volatile agents. In addition, to a role in anaesthesia, fentanyl is used in the management of severe pain states delivered by several routes of administration [1].

\section{Absorption, distribution, metabolism, and elimination of fentanyl}

These agents are highly lipid soluble and rapidly cross the blood-brainbarrier. This is reflected in the half-life for equilibration between the plasma and the cerebrospinal fluid of about $5 \mathrm{~min}$ for fentanyl and sulfentanil. The levels in plasma and cerebrospinal fluid decline rapidly to redistribution of fentanyl from highly perfused tissue groups to other tissues such as muscle and fat. As saturation of less well-perfused tissue occurs, the duration of effect of fentanyl and sulfentanil approaches the length of their elimination half-life is 3 to 4 hours. Fentanyl and sulfentanil undergo hepatic metabolism and renal excretion. With the use of higher doses or prolonged infusions, the drugs accumulate, these clearance mechanisms become progressively saturated, and fentanyl and sulfentanil become longer acting [1].

Pharmacologic effects of fentanyl, Effects on the cerebral nervous system

Fentanyl and its congeners are all extremely potent analgesics and typically exhibit a very short duration of action when given parenterally. As with other opioids, nausea, vomiting, and itching can be observed. Muscle rigidity, while possible after all narcotics, appears to be more common after the high doses used in anaesthetic induction. Rigidity can 
be treated with depolarizing or non-depolarizing neuromuscular-blocking agents, while controlling the patient's ventilation, but care must be taken sure that the patients are not simply immobilized and aware. Respiratory depression is similar to that observed with other MOR agonists but onset is more rapidly. As with analgesia, respiratory depression after small doses is of shorter duration than with morphine but of similar duration after large doses or lung infusions. Delayed respiratory depression also can be seen after the use of fentanyl or sulfentanil, possibly owing to enterohepatic circulation [1].

\section{Effects on the cardiovascular system}

Fentanyl and its derivatives decrease heart rate through vagal activation and may modestly decrease blood pressure. However, these drugs do not release histamine, and direct depressant effects on the myocardium are minimal. For this reason, high doses of fentanyl or sulfentanil are commonly used as the primary anaesthetic for patients undergoing cardiovascular surgery or for patients with poor cardiac function [1].

\section{Therapeutic use of fentanyl}

Fentanyl citrate and sulfentanil citrate have widespread popularity as anaesthetic adjuvants administered intravenously and epidurally. After systemic delivery, fentanyl is about 100 times more potent than morphine and sulfentanil is about 1,000 times more potent than morphine. The time to peak analgesic effect after intravenous administration of fentanyl and sulfentanil (about $5 \mathrm{~min}$ ) is notable less than that of morphine and meperidine (about $15 \mathrm{~min}$ ). Recovery from analgesic effects also occurs more quickly. However, with large doses or prolonged infusions, the effects of these drugs become more lasting, with durations of action becoming similar to those of longer-acting opioids. The use of fentanyl in chronic pain treatment has become more widespread. Transdermal patches that provide sustained release if fentanyl for 48 to 72 hours are available. However, factors promoting increased absorption (e.g., fever) can lead to relative overdosage and increased adverse-effects. Transbuccal absorption by the use of buccal tablets and lollipop-like lozenges permit rapid absorption and has found use in the management of acute incident pain and for the relief of breakthrough cancer pain. As fentanyl is poorly absorbed in the gastrointestinal tract, the optimal absorption is through buccal administration. Fentanyl should only be used in opioidtolerant patents, defined as consuming more than $60 \mathrm{mg}$ of oral morphine equivalent. Epidural use of fentanyl and sulfentanil for postoperative or labour analgesia is popular. A combination of epidural opioids with local anaesthetics permits reduction in the dosage of both compounds. Illicit use (self-administration by chewing) of fentanyl patches can be deadly, and practitioners must be aware of this potential and keep careful control of fentanyl stocks [1]. Fentanyl is used to provide perioperative pain relief. Remifentanil is a related very short acting alternative. A continuous infusion will cause tolerance to develop and exposes infants to symptoms of opiate withdrawal. Routine use of a continuous fentanyl infusion seems to offer little advantage over bolus prior to painful procedures in ventilated preterm newborns [2]. Fentanyl is used in analgesia, sedation, or anaesthesia. Fentanyl is a synthetic opioid narcotic analgesic that is 50 to 100 times more potent than morphine on a weight basis and fentanyl is extremely lipid soluble. Fentanyl penetrates the cerebral nervous system rapidly. Transient rebound in fentanyl serum concentration may reflect sequestration and subsequent release of fentanyl from body fat. Fentanyl is metabolized extensively in the liver by CYP3A4 enzyme system and then excreted by the kidney. Serum elimination of fentanyl is prolonged in infants with liver failure and it is highly bound to plasma protein. The distribution volume widely varies $(10$ to $30 \mathrm{~L} / \mathrm{kg}$ ) and the serum elimination half-life is 1 to 15 hours. It is recommended to monitor respiratory and cardiovascular status closely, and to observe the abdominal distention, loss of bowel sounds, and muscle rigidity [3].

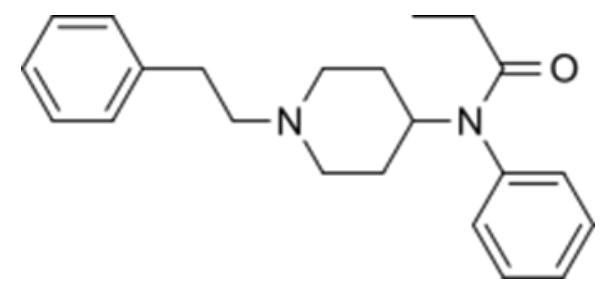

Fentanyl molecular structure $($ molecular weight $=336.471)$

\section{Literature search}

The literature search was performed electronically using PubMed database as search engine and the following key words were used: "fentanyl dosing infants, children", "fentanyl efficacy safety infants, children", "fentanyl effects infants, children", "fentanyl adverse-effects infants, children", "fentanyl metabolism", "fentanyl pharmacokinetics infants, children", "fentanyl drug interactions", "fentanyl treatment infants, children", "fentanyl trials infants, children", "fentanyl placental transfer", and "fentanyl breast-milk". In addition, the books: The Pharmacological Basis of Therapeutics [1], Neonatal Formulary [2], NEOFAX $^{\circledR}$ by Young and Mangum [3], and The British National Formulary for Children [4] are consulted.

\section{Results}

\section{Administration schedules of fentanyl to infants and children}

Intravenous administration to infants [2]

Short term use: Smaller doses (1 to $3 \mu \mathrm{g} / \mathrm{kg}$ ), given over 30 seconds, may be used to provide analgesia in the spontaneously breathing infant but $5 \mu \mathrm{g} / \mathrm{kg}$ intravenous dose will abolish respiration whilst providing good brief analgesia; twice this dose is effective for an hour. A low dose of 0.67 to $1 \mu \mathrm{g} / \mathrm{kg}$ is sometimes used during less invasive surfactant administration in the occasional infant who is seen to "struggle" during this procedure. The short duration of action of fentanyl means that the infant can be maintained on continuous positive airway pressure.

Sustained use: Give an initial intravenous injection of $5 \mu \mathrm{g} / \mathrm{kg}$, and then infuse intravenously at a rate of 1 to $1.5 \mu \mathrm{g} / \mathrm{kg} / \mathrm{hour}$. Adjust the dose according to response.

Use during therapeutic hypothermia: There are currently insufficient data from hypothermic newborns to recommend any specific dosing schedule, however it would seem sensible to begin by halving the "normthermic" dose (i.e., by giving $5 \mu \mathrm{g} / \mathrm{kg}$, and then infusing at 0.75 $\mu \mathrm{g} / \mathrm{kg} /$ hour) and titrating according to the response of the infant.

Administration to children [4]

Transdermal application for chronic intractable pain not currently treated with a strong opioid analgesic

Children aged 16 to 17 years. Give initially $12 \mu \mathrm{g} / \mathrm{kg} /$ hour every 72 hours, alternatively give initially $25 \mu \mathrm{g} / \mathrm{kg} /$ hour every 72 hours, when starting, evaluation of the analgesic effect should not be made before the system has been worn for 24 hours (to allow for the gradual increase in plasma fentanyl concentration) - previous analgesic therapy should be phased out gradually from time of first patch application, the dose should be adjusted at 24 to 72 hours intervals in step of 12 to $25 \mu \mathrm{g} / \mathrm{kg} /$ hour if necessary, more than one patch may be used at a time (but applied at the same time to avoid confusion) - consider additional or alternative analgesic therapy if the dose required exceeds $300 \mu \mathrm{g} / \mathrm{kg} /$ hour (important: it takes 17 hours or more for the plasma fentanyl concentration to decrease the dose by $50 \%$ - replacement opioid therapy should be intimately at a low dose and increased gradually).

Transdermal application for chronic intractable pain currently treated with a strong opioid analgesic 
Children aged 2 to 17 years. Give an initial dose based on previous 24 hour opioid requirement (consult product literature), for evaluating analgesic efficacy and dose increments.

Intravenous injection for spontaneous respiration: analgesia and enhancement of anaesthesia during operation

Children aged 1 month to 11 years. Give initially 1 to $3 \mu \mathrm{g} / \mathrm{kg}$, and then $1 \mu \mathrm{g} / \mathrm{kg}$ as required, the dose to be administered over at least 30 seconds. Children aged 12 to 17 years. Give initially 50 to $100 \mu \mathrm{g}$ (maximum per dose $=200 \mu \mathrm{g}$ ), the dose maximum on specialist advice, and then 25 to $50 \mu \mathrm{g}$ as required, the dose to be administered over at least 30 seconds. Intravenous injection of assisted ventilation: analgesia and enhancement of anaesthesia during operation

Children aged 1 month to 11 years. Give initially 1 to $5 \mu \mathrm{g} / \mathrm{kg}$, and then 1 to $3 \mu \mathrm{g} / \mathrm{kg}$ as required, the dose to be administered over at least 30 seconds.

Children aged 12 to 17 years. Give initially 1 to $5 \mu \mathrm{g} / \mathrm{kg}$, and then 50 to $200 \mu \mathrm{g}$ as required, the dose to be administered over at least 30 seconds. Intravenous injection of assisted ventilation: analgesia and respiratory depression in intensive care

Children. Give initially 1 to $5 \mu \mathrm{g} / \mathrm{kg}$, and then (by intravenous infusion) give 1 to $6 \mu \mathrm{g} / \mathrm{kg} / \mathrm{hour}$, adjust the dose according to the response.

Buccal administration using lozenges for breakthrough pain in children receiving opioid therapy for chronic cancer pain

Children aged 16 to 17 years. Give initially $200 \mu \mathrm{g}$, the dose to be given over $15 \mathrm{~min}$, and then $200 \mu \mathrm{g}$ after $15 \mathrm{~min}$ if required, no more than 2 dose units for each pain episode; if adequate pain relief not achieved with 1 dose unit for consecutive breakthrough pain episode, increase the strength of the dose unit until adequate pain relief achieved with 4 lozenges or less daily, if more than 4 episodes of breakthrough pain each day, adjust background analgesia.

\section{Efficacy and safety of fentanyl in infants and children}

In very preterm infants on mechanical ventilation, continuous fentanyl infusion is efficacy and safe in reducing acute pain [5]. Oral administration of fentanyl $30 \mathrm{~min}$ before entrance to the holding room for an operation is found efficacy and safe in children in reducing pain [6]. Intranasal fentanyl is found effective and safe in infants and reduces pain and does not induce adverse-effects [7]. Intranasal fentanyl is a safe and effective medication for the treatment of acute attacks of respiratory distress in children with life-limiting conditions [8]. Intranasal fentanyl, at a dose of $1.5 \mu \mathrm{g} / \mathrm{kg}$, is a safe and effective analgesic in the prehospital management of acute severe pain in children and may be an attractive alternative to both oral and intravenous opiates [9]. Intranasal fentanyl has proven to be useful in both in-hospital and out-of-hospital pain management settings of pain [10]. Intranasal fentanyl, at doses of 50, 100, and $200 \mu \mathrm{g}$, is associated with an onset of activity at 10 minutes and effective treatment of breakthrough pain compared with placebo [11]. Intranasal fentanyl is an effective, safe and well tolerated mode of analgesia for children aged 1 to 3 years with moderate to severe pain [12]. Intranasal fentanyl has been found safe and efficacy in reducing acute pain in children [13].

\section{Effects of fentanyl in infants and children}

Administration of fentanyl bolus for procedural pain and sedation is not shown to significantly affect cerebral oxygenation, cerebral tissue oxygen extraction, or cardiac output in stable preterm infants [14]. Fentanyl added to epidural bupivacaine infusions during labour does not depress neonatal respiration or adversely affect neurobehavioral scores and other indices of neonatal welfare [15]. The use of intranasal fentanyl during halothane or sevoflurane anaesthesia for tympanosotomy tube placement is associated with diminished postoperative agitation without an increase in vomiting, hypoxemia, or discharge times [16]. There are significant correlations between fentanyl dosage and Neonatal Abstinence Score Tool score $(r=0.76, \mathrm{P}$-value $<0.01)$, between length of infusion of fentanyl and Neonatal Abstinence Score Tool score ( $\mathrm{r}=0.70$, P-value < $0.05)$, and between chloral hydrate dosage and Neonatal Abstinence Score Tool score $(\mathrm{r}=0.62, \mathrm{P}$-value < 0.05) [17].

Common or very common adverse-effects caused by fentanyl in infants and children [4]

With parenteral use: apnoea, hypertension, movement disorders, muscle rigidity, post procedural complications, respiratory disorders, and vascular pain. With transdermal use: anxiety, appetite decreased, asthenia, depression, diarrhoea, dyspnoea, gastrointestinal discomfort, hypertension, insomnia, malaise, muscle complains, peripheral oedema, sensation abnormal, temperature sensation altered, and tremor.

Uncommon adverse-effects caused by fentanyl in infants and children [4]

With parenteral use: airway complication of anaesthesia, chills, hiccups, and hypothermia. With transdermal use: consciousness impaired, cyanosis, fever, gastrointestinal disorders, influenza like illness, memory loss, respiratory disorders, seizures, sexual dysfunction, and vision blurred.

Rare or very rare adverse-effects caused by fentanyl in infants and children [4]

With transdermal use: apnoea.

Adverse-effects caused by fentanyl in infants and children whose frequency is not known [4]

With buccal use: adrenal insufficiency, androgen deficiency, anxiety, appetite decreased, asthenia, coma, depersonalization, depression, diarrhoea, dyspnoea, emotional lability, fever, gait abnormal, gastrointestinal discomfort, gastrointestinal disorders, gingival haemorrhage, gingivitis, injury, loss of consciousness, malaise, myoclonus, oral disorders, peripheral oedema, seizures, sensation abnormal, sleep disorders, speech slurred, taste altered, thinking abnormal, throat oedema, vasodilation, vision disorders, weight decreased, and withdrawal syndrome neonatal. With parenteral use: biliary spasm, cardia arrest, cough, hyperalgesia, loss of consciousness, and seizure. With transdermal use: myoclonus, and withdrawal syndrome neonatal.

\section{Fentanyl metabolism}

CYP3A4*1G genetic polymorphism affects the metabolic-rate of fentanyl. There is a positive correlation between CYP3A4 mRNA level and metabolic-rate of fentanyl [18]. CYP3A4 is the major catalyst involved in fentanyl oxidation to norfentanyl in human liver [19]. Human intestinal and liver microsomes catalyse fentanyl metabolism and the enzyme which metabolizes fentanyl is CYP3A4 [20].

\section{Pharmacokinetics of fentanyl in infants and children}

Ziesenitz et al. [21] reviewed the pharmacokinetics of fentanyl in 51 infants and children aged 0 to 1 month to $9.5 \pm 2.8$ years, and fentanyl dose is reported in table 1 . 


\begin{tabular}{|l|l|l|l|l|l|l|}
\hline $\mathrm{N}$ & Age & Weight $(\mathrm{kg})$ & $\begin{array}{l}\text { Dose } \\
(\mu \mathrm{g} / \mathrm{kg})\end{array}$ & $\begin{array}{l}\text { TBC } \\
(\mathrm{ml} / \mathrm{min} / \mathrm{kg})\end{array}$ & $\begin{array}{l}\text { Elimination } \\
\text { half-life }(\mathrm{min})\end{array}$ & $\begin{array}{l}\text { DV } \\
(\mathrm{L} / \mathrm{kg})\end{array}$ \\
\hline 2 & $1 \pm 0$ days & $3.2 \pm 1.1$ & $30.3 \pm 16.0$ & $16.2 \pm 2.59$ & $294 \pm 113$ & $5.94 \pm 1.47$ \\
\hline 2 & $7 \pm 0.06$ months & $6.0 \pm 1.2$ & $19.1 \pm 14.5$ & $18.1 \pm 1.41$ & $233 \pm 137$ & 0 to $1 \mathrm{month}$ \\
\hline 6 & $\begin{array}{l}3.17 \pm 0.68 \\
\text { years }\end{array}$ & $17.3 \pm 3.4$ & $10.1 \pm 3.1$ & $11.5 \pm 4.19$ & $244 \pm 79$ & $3.06 \pm 1.02$ \\
month to 1 \\
year
\end{tabular}

$\mathrm{TBC}=$ total body clearance. $\mathrm{DV}=$ distribution volume. *Fentanyl was intravenously infused.

Table 1: Pharmacokinetic parameters of fentanyl which are obtained in infants and children. Fentanyl was administered by intravenous bolus or by intravenous infusion. Figures are the mean \pm SEM or median and (range), by Ziesenitz et al. [21].

Fentanyl plasma concentrations after an intravenous bolus (about $30 \mu \mathrm{g} / \mathrm{kg}$ ) are found to be lower in infants than in children and these findings may result from a larger distribution volume or age-related differences in protein binding. An increase in the total body clearance probably reflects maturation of CYP enzymes suggesting that the Michaelis-Menten constant is age dependent. In newborn infants and in older infants during non-cardiac surgery, the total body clearance increases with age, with the most rapid increase at a postnatal age of 2 weeks, whereas the distribution volume and the elimination half-life do not change after a bolus of $54.1 \pm 2.3 \mu \mathrm{g} / \mathrm{kg}$. After a fentanyl continuous infusion, the elimination half-life is prolonged and the distribution volume at steady-state is increased due to a slow redistribution from peripheral compartments. The total body clearance is higher in children aged 6 months to 6 years compared to younger or older children ( 8.2 versus 18.9 versus $8.0 \mathrm{ml} / \mathrm{min} / \mathrm{kg}$ ) which is attributed to increase liver metabolism.

\section{Interaction of fentanyl with drugs}

A patient using a fentanyl patch was started on a course of clarithromycin and experienced a respiratory arrest 2 days later [22]. Fentanyl and clarithromycin are metabolized by CYP3A4 and following the co-administration of these drugs clarithromycin inhibits fentanyl metabolism and induces respiratory depression and death [23]. Two infants developed chest wall rigidity following the co-administration of neuromuscular blocking with fentanyl [24]. A patient who received amitriptyline and fentanyl reported an adverse-reaction [25]. Fentanyl is metabolized by CYP3A4 and the coadministration of fentanyl with drugs which are metabolized by this enzyme inhibits fentanyl metabolism and results in excess of fentanyl serum concentration enhancing fentanyl effects [26]. Diltiazem and fentanyl are metabolized by CYP3A4; fentanyl inhibits the metabolism of diltiazem and induces delirium [27]. The co-administration of ranitidine and fentanyl increases the risk of seizures [28]. Fentanyl inhibits the P-glycoprotein-mediated digoxin transport in Caco-2 cells with $\mathrm{IC}_{50}$ value of $6.5 \mu \mathrm{M}$ [29]. The dose of tacrolimus was reduced from 1.28 to $0.68 \mathrm{ml} / \mathrm{min} / \mathrm{kg}$ when it was combined with fentanyl as tacrolimus and fentanyl are metabolized by CYP3A4 [30].

\section{Treatment of infants and children with fentanyl}

Fentanyl treatment of newborn infants during therapeutic hypothermia contributes to ameliorate neuroprotection in asphyxiated cooled newborns [31]. Fentanyl combined with midazolam is safe and more effective than midazolam alone for sedation therapy in mechanically ventilated children [32]. Enteral administration of methadone may expedite fentanyl discontinuation and reduce the risk of withdrawal in critically ill children at high risk for opioid abstinence syndrome [33]. Transdermal fentanyl is a useful opioid-agonist for the treatment of moderate to severe chronic cancer pain [34]. Treatment of children with therapeutic transdermal fentanyl is feasible and well tolerated [35]. Prophylactic fentanyl-droperidol prolongs the lengthto-stay and recovery time and provides no discrete identifiable benefit over acetaminophen alone in paediatric strabismus repair [36].

\section{Trials with fentanyl in infants and children}

In very preterm infants on mechanical ventilation, continuous fentanyl infusion protects the developing brain by relieving pain during the first 72 hours of mechanical ventilation [37]. Higher cumulative fentanyl dose in preterm infants correlated with a higher incidence of cerebellar injury and lower cerebellar diameter [38]. Integrated pharmacokinetic/pharmacodynamic modelling showed that the usually prescribed dosage regimens of fentanyl in neonates may not always provide the optimum degree of sedation [39]. A short course of low dose fentanyl infusion reduces behavioural sedation scores, $\mathrm{O}_{2}$ desaturations, and neuroendocrine stress response in preterm ventilated infants [40]. Fentanyl is a more effective analgesic agent than morphine and causes fewer adverse-effects than morphine. Fentanyl is superior to morphine for short-term postnatal analgesia in newborn infants [41]. The current analyses indicate that fentanyl around the end of surgery reduces the incidence of emergence agitation in children undergoing general anaesthesia [42]. A meta-analysis suggests that fentanyl decreases the incidence of emergence agitation under sevoflurane anaesthesia in children and postoperative pain but has a higher incidence of postoperative nausea and vomiting [43].

\section{Transfer of fentanyl across the human placenta}


The mean umbilical vein to maternal fentanyl ratios is 1.12 for total drug and 1.20 for the free drug and values are unrelated to the last epidural bolus to delivery interval [44]. There is rapid transfer of fentanyl to the fetus in early pregnancy and the drug remains in foetal tissue for some time after the initial dose is given to the mother [45]. Fentanyl rapidly transfers across the early placenta into the amniotic cavity and foetal blood circulation [46]. Fentanyl is detected in the foetal blood $1 \mathrm{~min}$ after dosing and peaks at $5 \mathrm{~min}$ [47]. Thirty paired samples were obtained from healthy pregnant women and foetuses and the foetal to maternal fentanyl plasma concentration ratio ranges between 0.23 and 0.73 indicating fentanyl crosses the human placenta [48].

\section{Migration of fentanyl into the breast-milk}

Nitsun et al. [49] studied the pharmacokinetics of fentanyl in the breast-milk of 5 lactating women on the $11 \pm 4$ weeks of post-partum. Fentanyl was intravenously infused at a dose of $100 \mu \mathrm{g}$ and the concentration of fentanyl in the breast-milk was measured 4, 7, 9, 11, and 24 hours after fentanyl dosing.

\begin{tabular}{|l|l|l|l|l|}
\hline Value & $\begin{array}{l}\text { Dose } \\
(\mu \mathrm{g})\end{array}$ & $\begin{array}{l}\text { Fentanyl amount recovered in the } \\
\text { breast-milk }(\mu \mathrm{g})\end{array}$ & $\begin{array}{l}\text { Fraction of fentanyl maternal dose transferred } \\
\text { to the breast-milk }\end{array}$ & $\begin{array}{l}\text { Weight-normalized infant dose of } \\
\text { fentanyl }(\mu \mathrm{g} / \mathrm{kg})\end{array}$ \\
\hline Median & 100 & 0.024 & 0.24 & 0.005 \\
\hline Range & --- & 0.0060 to 0.073 & 0.06 to 0.73 & 0.001 to 0.015 \\
\hline
\end{tabular}

Table 2. Fentanyl migration into breast-milk within 24 hour $(\mathrm{N}=5)$. Figures are the median and range, by Nitsun et al. [49].

This table shows that the maximum exposure of fentanyl to the nursing infants is $<0.1 \%$.

Leuschen et al. [50] studied the migration of fentanyl into the breast-milk of 10 lactating women and observed a lack of substantial fentanyl excretion into the breast-milk after short-term maternal fentanyl exposure.

\section{Discussion}

Fentanyl is a systemic opioid related to phenylpiperidines and it is used in anaesthetics and in analgesia and the analgesic effects is about 100 times higher than that of morphine. Fentanyl is highly lipid soluble and rapidly crosses the blood-brain-barrier and it is rapidly eliminated in plasma and cerebrospinal fluid. Fentanyl may cause nausea, vomiting, itching, muscle rigidity, respiratory depression, and decreases heart rate through vagal activation. Fentanyl may be administered intravenously, orally, and by buccal, transdermal and intranasal applications, and the oral bioavailability is poor whereas the bioavailability following buccal administration is good [1]. In infants, fentanyl is given intravenously for short and sustained uses and during therapeutic hypothermia. For the short and sustained uses the fentanyl dose is 1 to $3 \mu \mathrm{g} / \mathrm{kg}$ and $5 \mu \mathrm{g} / \mathrm{kg}$, respectively. For the treatment of hypothermia fentanyl is given at a dose of $5 \mu \mathrm{g} / \mathrm{kg}$ followed by an infusion of $0.75 \mu \mathrm{g} / \mathrm{kg} / \mathrm{hour}$ [2]. In children, fentanyl may be given intravenously, by transdermal application, and by buccal administration and the dose varies according to child age and body-weight [4]. Fentanyl has been found efficacy and safe in infants and children [5-13]. Continuous infusion of fentanyl is found efficacy and safe in reducing acute pain in preterm infants maintained on mechanical ventilation [5]. Oral fentanyl administered $30 \mathrm{~min}$ before starting surgery is efficacy and safe in reducing pain [6]. Intranasal fentanyl has been found efficacy and safe in reducing pain in infants without inducing adverse-effects [7], and in treatment of acute attacks of respiratory distress in children with life-limiting conditions [8]. Intranasal fentanyl, administered at a dose of $1.5 \mu \mathrm{g} / \mathrm{kg}$, is an effective and safe analgesic agent in reducing acute severe pain in children [9] and in the management of pain in both in-hospital and out-hospital children [10]. Intranasal fentanyl, at doses of 50,100 , or $200 \mu \mathrm{g}$, is an effective treatment of breakthrough pain [11], and intranasal fentanyl treats moderate to severe pain in children [12, 13]. Fentanyl causes different adverse-effects in infants and children [4]. Fentanyl produces different effects in infants and children [14-17]. Intravenous fentanyl reduces pain and induces sedation in infants and does not affect cerebral oxygenation or cardiac output in preterm infants [14], and fentanyl co-administered with bupivacaine during labour does not depress neonatal respiratory or adversely affect neurobehavioral scores in infants [15]. Intranasal fentanyl use during halothane or sevoflurane anaesthesia for tympanosotomy tube placement is associated reduced postoperative agitation without increase adverseeffects or discharge times [16]. There are significant correlations between fentanyl dosage and Neonatal Abstinence Score Tool [17]. Fentanyl is metabolized into norfentanyl by liver and intestinal CYP3A4 [18-20] and CYP3A4*1G genetic polymorphism affects the metabolic-rate of fentanyl [18]. The pharmacokinetics of fentanyl have been studied in infants and children [21]. The elimination half-life ranges from 208 to $1,266 \mathrm{~min}$ suggesting that fentanyl is rapidly cleared from the body and the distribution volume ranges from 1.92 to $15.2 \mathrm{~L} / \mathrm{kg}$. The remarkable variation in the elimination half-life and distribution volume is accounted by the wide variation in infants and children demographic characteristics. Fentanyl interacts with drugs [22-30]. Fentanyl and clarithromycin are metabolized by CYP3A4, and clarithromycin inhibits the metabolism of fentanyl and induce respiratory depression and death [22, 23]. The combination of fentanyl with neuromuscular blocking agents causes chest wall rigidity in two infants [24], and the co-administration of amitriptyline with fentanyl causes adverse-reactions [25]. Fentanyl is metabolized by CYP3A4 and the combination of drugs which are metabolized by this enzyme inhibits fentanyl metabolism causing excessive serum concentrations of fentanyl enhancing fentanyl effects [26]. Diltiazem and fentanyl are metabolized by CYP3A4 and fentanyl inhibits the metabolism of diltiazem causing high serum concentration of diltiazem which induces delirium [27]. The co-administration of fentanyl with ranitidine induces the risk of seizures [28]. Fentanyl inhibits the Pglycoprotein-mediated digoxin in Caco-2 cells [29]. Tacrolimus is metabolized by CYP3A4 and the combination of tacrolimus with fentanyl increase tacrolimus serum concentration and the dose of tacrolimus must be reduced when tacrolimus is co-administered with fentanyl [30]. The treatment of infants and children with fentanyl has been studied [31-36]. Fentanyl treatment of newborn infants during therapeutic hypothermia ameliorates neuroprotection in asphyxiated cooled newborn infants [31]. Fentanyl combined with midazolam is safe and more effective than midazolam alone for sedation therapy in mechanical ventilated children [32]. Enteral administration of methadone expedites fentanyl discontinuous and reduces the risk of withdrawal in critically ill children at high risk for opioid abstinence syndrome [33]. Transdermal fentanyl is useful for the treatment of moderate to severe chronic cancer pain [35], and the prophylactic fentanyl-droperidol prolongs the length-to-stay and recovery time and provides no discrete benefit over acetaminophen alone in paediatric strabismus repair [36]. The trials with fentanyl have been extensively reported in infants and children [37-43]. In preterm infants on mechanical ventilation, fentanyl protects the developing brain shortly after mechanics ventilation [37]. High cumulative fentanyl dose correlates 
with a higher incidence of cerebellar injury and lower cerebellar diameter in preterm infants [38]. Integrated pharmacokinetic/pharmacodynamic modelling showed that the dosing regimen of fentanyl in neonates may not provide the optimum sedation [39]. A short course of low dose fentanyl infusion reduces behavioural sedation, $\mathrm{O}_{2}$ desaturation, and neuroendocrine stress in preterm ventilated infants [40]. Fentanyl used for analgesia is superior to morphine produces fewer adverse-effects than morphine and it is superior to morphine for short-term postnatal analgesia in newborn infants [41]. Fentanyl reduces the incidence of emergence agitation in children undergoing general anaesthesia [42], and fentanyl decreases the incidence of agitation under sevoflurane anaesthesia in children and reduces postoperative pain but has a higher incidence of postoperative nausea and vomiting [43]. Fentanyl freely crosses the human placenta [44-48] and poorly migrates into the breast-milk [49-50]. In conclusion, fentanyl is a systemic opioid related to the phenylpiperidines and it is used in anaesthetic practice and in analgesia. The analgesic effect of fentanyl is about 100 times more potent than that of morphine. Fentanyl is highly lipid soluble, rapidly crosses the bloodbrain-barrier, and the time to peak analgesic effect after intravenous administration is about $5 \mathrm{~min}$. Following intravenous administration fentanyl is rapidly eliminated in plasma and in cerebrospinal fluid. Fentanyl may be administered intravenously, orally, or by intranasal, transdermal, or buccal application, the oral bioavailability is poor whereas the bioavailability following buccal administration is good. Fentanyl may cause nausea, vomiting, itching, and rigidity and the last is treated with neuromuscular-blocking agents. Fentanyl may decrease heart rate through vagal activation and may modestly decrease blood pressure. In infants, intravenous fentanyl is administered for short use, for sustained use, and during therapeutic hypothermia. In children, fentanyl is administered by intravenously or by transdermal or buccal application and fentanyl dose varies according to the child age and body-weight. Fentanyl has been found efficacy and safe in infants and children but it may cause adverseeffects. The effects caused by fentanyl, the treatment of infants and children with fentanyl, and the trials conducted with fentanyl in infants and children have been extensively studied. The pharmacokinetics of infants have been studied in infants and children and the elimination halflife of fentanyl ranges from 208 to 1,266 min suggesting that fentanyl is rapidly eliminated. Fentanyl is metabolized by CYP3A4 in both human liver and intestine and fentanyl interacts with drugs. Some interactions occur with drugs which are metabolized by CYP3A4; the coadministration of these drugs with fentanyl affect the fentanyl metabolism or pharmacokinetics. Fentanyl freely crosses the human placenta and poorly migrates into the beast-milk. The aim of this study is to review the clinical pharmacology of fentanyl in infants and children.

\section{Conflict of interests}

The authors declare no conflicts of financial interest in any product or service mentioned in the manuscript, including grants, equipment, medications, employments, gifts, and honoraria.

This article is a review and drugs have not been administered to men or animals.

\section{Acknowledgments}

The author thanks Dr. Patrizia Ciucci and Dr. Francesco Varricchio, of the Medical Library of the University of Pisa, for retrieving the scientific literature.

\section{References}

1. Yaksh T, Wallace M. (2018) "Opioids, Analgesia, and Pain Management”. In The Goodman \& Gilman's. The Pharmacological Basis of the Therapeutics, Brunton Hilal- dandan LL, Knollmann BC, editors. Mc Graw Hill, 13th Edition, USA, New York, pp. 355-386.

2. Neonatal Formulary. (2020) "Fentanyl". Oxford University Press. 8th Edition, Great Clarendon Street, Oxford, OX2, 6DP, UK, pp: 308-310\.

3. Young TE, Mangum B. NEOFAX .(2010) "Fentanyl" Thomas Reuters Clinical Editorial Staff, 23rd Edition, Montvale, USA, pp: 206-207.

4. The British national formulary for children. (2020) "Fentanyl". Macmillan, 78th Edition, Hampshire International Business Park, Hampshire, Lime Three Way, Basingstoke, Hampshire, UK, 2019-pp: 286-287.

5. Ancora G, Lago P, Garetti E, Pirelli A, Merazzi D, Mastrocola M, et al. Efficacy and safety of continuous infusion of fentanyl for pain control in preterm newborns on mechanical ventilation. J Pediatr. 163(3): 645-651.

6. Tamura M, Nakamura K, Kitamura R, Kitagawa S, Mori N, Ueda Y. (2013) Oral premedication with fentanyl may be a safe and effective alternative to oral midazolam. Eur J Anaesthesiol. 20(6): 482-486.

7. Harlos MS, Stenekes S, Lambert D, Hohl C, Chochinov MH. (2013) Intranasal fentanyl in the palliative care of newborns and infants. J Pain Symptom Manage. 46(2): 265-274.

8. Pieper L, Wager J, Zernikow B. (2018) Intranasal fentanyl for respiratory distress in children and adolescents with lifelimiting conditions. BMC Palliat Care. 17(1): 106. doi: 10.1186 .

9. . Murphy AP, Hughes M, Mccoy S, Crispino G, Wakai A, O'Sullivan R. Intranasal fentanyl for the prehospital management of acute pain in children. Eur J Emerg Med. 2017; 24(6): 450-454.

10. Prommer E, Thompson L. (2011) Intranasal fentanyl for pain control: current status with a focus on patient considerations. Patient Prefer Adherence. 5(3): 157-164.

11. Kress HG, Orońska A, Kaczmarek Z, Kaasa S, Colberg T, Nolte T. (2009) Efficacy and tolerability of intranasal fentanyl spray 50 to 200 microg for breakthrough pain in patients with cancer: a phase III, multinational, randomized, double-blind, placebocontrolled, crossover trial with a 10-month, open-label extension treatment period. Clin Ther. 31(6): 1177-1191.

12. Cole J, Shepherd M, Young P. (2009) Intranasal fentanyl in 13-year-olds: a prospective study of the effectiveness of intranasal fentanyl as acute analgesia. Emerg Med Australas. 21(5): 395-400.

13. Borland ML, Jacobs I, Geelhoed G. (2002) Intranasal fentanyl reduces acute pain in children in the emergency department: a safety and efficacy study. Emerg Med (Fremantle). 14(3): 275280.

14. Mitra S, M Babadagli E, Hatfield T, dePalma A, McCord H, ElNaggar W, et al. (2020) Effect of Fentanyl Boluses on Cerebral Oxygenation and Hemodynamics in Preterm Infants: A Prospective Observational Study. Neonatology. 117(4): 480487.

15. Porter J, Bonello E, Reynolds F. (1998) Effect of epidural fentanyl on neonatal respiration. Anesthesiology. 89(1): 79-85.

16. Galinkin JL, Fazi LM, Cuy RM, Chiavacci RM, Kurth CD, Shah UK, et al. (2000) Use of intranasal fentanyl in children undergoing myringotomy and tube placement during halothane and sevoflurane anesthesia. Anesthesiology. 93(6): 1378-1383.

17. French JP, Nocera M. (1994) Drug withdrawal symptoms in children after continuous infusions of fentanyl. J Pediatr Nurs. 9(2): 107-113. 
18. Yuan J-J, Hou J-K, Zhang W, Chang Y-Z, Li Z-S, Wang Z-Y, et al. (2015) CYP3A4*1G Genetic Polymorphism Influences Metabolism of Fentanyl in Human Liver Microsomes in Chinese Patients. Pharmacology. 96(1-2): 55-60.

19. Feierman DE, Lasker LM. (1996) Metabolism of fentanyl, a synthetic opioid analgesic, by human liver microsomes. Role of CYP3A4. Drug Metab Dispos. 24(9): 932-939.

20. Labroo RB, Paine MF, Thummel KE, Kharasch ED. (1997) Fentanyl metabolism by human hepatic and intestinal cytochrome P450 3A4: implications for interindividual variability in disposition, efficacy, and drug interactions. Drug Metab Dispos. 25(9): 1072-1080.

21. Ziesenitz V, Vaughns JD, Koch G, Mikus G, van den Anker JN. (2018) Pharmacokinetics of Fentanyl and Its Derivatives in Children: A Comprehensive Review. Clin Pharmacokinet. 57(2): 125-149.

22. Cronnolly B, Pegrum H. (2012) Fentanyl-clarithromycin interaction. BMJ Case Rep. bcr0220125936. doi: 10.1136.

23. Horton R, Barber C. (2009) Opioid-induced respiratory depression resulting from transdermal fentanyl-clarithromycin drug interaction in a patient with advanced COPD. J Pain Symptom Manage. 37(6): e2-e5.

24. Dewhirst E, Naguib A, Tobias JD. (2012_ Chest wall rigidity in two infants after low-dose fentanyl administration. Pediatr Emerg Care 28(5): 465-468.

25. Samartzis L, Savvari P, Kontogiannis S, Dimopoulos S. (2013) Linezolid is associated with serotonin syndrome in a patient receiving amitriptyline, and fentanyl: a case report and review of the literature. Case Rep Psychiatry. 617251. doi: $10.1155 / 2013$.

26. Overholser BR, Foster DR. Opioid pharmacokinetic drug-drug interactions. (2011) Am J Manag Care. 17(Suppl 11): S276S287.

27. Levin TT, Bakr MH, Nikolova T. (2010) Case report: delirium due to a diltiazem-fentanyl CYP3A4 drug interaction. Gen Hosp Psychiatry. 32(6): e648-e610.

28. Moreira MB, da Rosa Mesquita MG, Stipp MAC, Paes GO. (2017) Potential intravenous drug interactions in intensive care. Rev Esc Enferm USP. 51: e03233. doi: 10.1590.

29. Wandel C, Kim R, Wood M, Wood A. (2002) Interaction of morphine, fentanyl, sufentanil, alfentanil, and loperamide with the efflux drug transporter P-glycoprotein. Anesthesiology. 96(4): 913-920.

30. Kitazawa F, Fuchida S-I, Kado Y, Ueda K, Kokufu T, Okano A, et al. (2017) Pharmacokinetic Interaction Between Tacrolimus and Fentanyl in Patients Receiving Allogeneic Hematopoietic Stem Cell Transplantation. Ann Transplant. 22(9): 575-580.

31. Lugli L, Spada C, Garetti E, Guidotti I, Roversi MF, Casa E, et al. (2021) Fentanyl analgesia in asphyxiated newborns treated with therapeutic hypothermia. J Matern Fetal Neonatal Med. 17. doi: 10.1080 .

32. Lee B, Park JD, Choi YH, Han YJ, Dong DI. (2019) Efficacy and Safety of Fentanyl in Combination with Midazolam in Children on Mechanical Ventilation. J Korean Med Sci. 34(3): e21. doi: 10.3346 .

33. Lugo RA, MacLaren R, Cash J, Pribble CG, Vernon DD. (2001) Enteral methadone to expedite fentanyl discontinuation and prevent opioid abstinence syndrome in the PICU. Pharmacotherapy. 21(12): 1566-1573.

34. Muijsers RB, Wagstaff AJ. (2001) Transdermal fentanyl: an updated review of its pharmacological properties and therapeutic efficacy in chronic cancer pain control. Drugs. 61(15): 2289-2307.

35. Collins JJ, Dunkel IJ, Gupta SK, Inturrisi CE, Lapin J, Palmer LN, et al. (1999) Transdermal fentanyl in children with cancer pain: feasibility, tolerability, and pharmacokinetic correlates. $J$ Pediatr. 134(3): 319-323.

36. Padda GS, Cruz OA, Krock JL. (1997) Comparison of postoperative emesis, recovery profile, and analgesia in pediatric strabismus repair. Rectal acetaminophen versus intravenous fentanyl-droperidol. Ophthalmology.104(3): 419424.

37. Qiu J, Zhao L, Yang Y, Zhang J-H, Feng Y, Cheng R. Effects of fentanyl for pain control and neuroprotection in very preterm newborns on mechanical ventilation. J Matern Fetal Neonatal Med. 2019; 32(22): 3734-3740.

38. McPherson C, Haslam M, Pineda R, Rogers C, Neil JJ, Inder TE. Brain Injury and Development in Preterm Infants Exposed to Fentanyl. Ann Pharmacother. 2015; 49(12): 1291-1297.

39. Encinas E, Calvo R, Lukas JC, Vozmediano V, Rodriguez M, Suarez E. A predictive pharmacokinetic/pharmacodynamic model of fentanyl for analgesia/sedation in neonates based on a semi-physiologic approach. Paediatr Drugs. 2013; 15(3): 247257.

40. Lago P, Benini F, Agosto C, Zacchello F. Randomised controlled trial of low dose fentanyl infusion in preterm infants with hyaline membrane disease. Arch Dis Child Fetal Neonatal Ed. 1998; 79(3): F194-F197.

41. Saarenmaa E, Huttunen P, Leppäluoto J, Meretoja O, Fellman $\mathrm{V}$. Advantages of fentanyl over morphine in analgesia for ventilated newborn infants after birth: A randomized trial. J Pediatr. 1999; 134(2): 144-150.

42. Kim N, Park JH, Seok Lee S, Choi T, Kim M-S. Effects of intravenous fentanyl around the end of surgery on emergence agitation in children: Systematic review and meta-analysis. Paediatr Anaesth. 2017; 27(9): 885-892.

43. Shi F, Xiao Y, Xiong W, Zhou Q, Yang P, Huang X. Effects of Fentanyl on Emergence Agitation in Children under Sevoflurane Anesthesia: Meta-Analysis of Randomized Controlled Trials. PLoS One. 2015; 10(8): e0135244.

44. Fernando R, Bonello E, Gill P, Urquhart J, Reynolds F, Morgan B. Neonatal welfare and placental transfer of fentanyl and bupivacaine during ambulatory combined spinal epidural analgesia for labour. Anaesthesia. 1997; 52(6): 517-524.

45. Cooper J, Jauniaux E, Gulbis B, Quick D, Bromley L. Placental transfer of fentanyl in early human pregnancy and its detection in fetal brain. Br J Anaesth. 1999; 82(6): 929-931.

46. Shannon C, Jauniaux E, Gulbis B, Thiry P, Sitham M, Bromley L. Placental transfer of fentanyl in early human pregnancy. Hum Reprod. 1998; 13(8): 2317-2320.

47. Craft JB Jr, Coaldrake LA, Bolan JC, Mondino M, Mazel P, Gilman RM, et al. Placental passage and uterine effects of fentanyl. Anesth Analg. 1983; 62(10): 894-898.

48. Fleet J-A, Belan I, Gordon AL, Cyna AM. Fentanyl concentration in maternal and umbilical cord plasma following intranasal or subcutaneous administration in labour. Int J Obstet Anesth. 2020; 42(5): 34-38.

49. Nitsun M, Szokol JW, Saleh J, Murphy GS, Vender JS, Luong L, et al. Pharmacokinetics of midazolam, propofol, and fentanyl transfer to human breast milk. Clin Pharmacol Ther. 2006; 79(6): 549-557.

50. Leuschen MP, Wolf LJ, Rayburn WF. Fentanyl excretion in breast milk. Clin Pharm. 1990; 9(5): 336-337. 
This work is licensed under Creative Commons Attribution 4.0 License

To Submit Your Article Click Here: Submit Manuscript

DOI: $10.31579 / 2690-8808 / 099$
Ready to submit your research? Choose Auctores and benefit from:

$>$ fast, convenient online submission

$>$ rigorous peer review by experienced research in your field

$>$ rapid publication on acceptance

$>$ authors retain copyrights

$>$ unique DOI for all articles

$>$ immediate, unrestricted online access

At Auctores, research is always in progress.

Learn more auctoresonline.org/journals/journal-of-clinical-case-reportsand-studies 